\title{
The Recombinant Human Secretory Leukocyte Protease Inhibitor (SLPI) protects cardiac fibroblasts injury against an in vitro ischemia/reperfusion injury
}

\author{
Nitchawat Paiyabhroma ${ }^{1}$, Nitirut Nernpermpisooth ${ }^{1,2}$, Sarawut Kumphune ${ }^{1,3, *}$ \\ ${ }^{1}$ Biomedical Research Unit in Cardiovascular Sciences (BRUCS), Faculty of Allied Health Sciences, Naresuan University, Phitsanulok, 65000, Thailand. \\ ${ }^{2}$ Department of Cardio-Thoracic Technology, Faculty of Allied Health Sciences, Naresuan University, Phitsanulok, 65000, Thailand. \\ ${ }^{3}$ Department of Medical Technology, Faculty of Allied Health Sciences, Naresuan University, Phitsanulok, 65000, Thailand.
}

\begin{tabular}{l}
\hline ARTICLE INFO \\
\hline Article history: \\
Received on: 14/03/2018 \\
Accepted on: 16/04/2018 \\
Available online: $29 / 06 / 2018$ \\
\\
\hline Key words: \\
Ischemia/reperfusion injury, \\
secretory leukocyte protease \\
inhibitor, cardiac fibroblast, \\
rhSLPI, cardioprotection.
\end{tabular}

\section{INTRODUCTION}

One of the key mechanisms of cardiac cell death during myocardial ischemia/reperfusion $(\mathrm{I} / \mathrm{R})$ injury is the overproduction of protease enzymes, which can be secreted from not only infiltrated leukocytes but also cardiomyocytes and cardiac fibroblast itself (Boudoulas and Hatzopoulos, 2009; Epelman et al., 2015). These protease enzymes cause cellular necrosis, both located within and around the ischemic area (Jordan et al., 1999). Therefore, prevention or attenuation of the protease enzyme activity caused by myocardial I/R injury is one of the most promising therapeutic targets for ischemic heart disease (IHD). The beneficial effects

\footnotetext{
"Corresponding Author Sarawut Kumphune, Department of Medical Technology, Biomedical Research Unit in Cardiovascular Sciences, Faculty of Allied Health Sciences, Naresuan University, 99 Moo 9, Phitsanulok, Phitsanulok 65000, Thailand.E-mail: sarawutk@nu.ac.th
}

of rhSLPI in ischemia/reperfusion injury was reported in cardiac transplantation (Schneeberger et al., 2008). In addition, our unpublished data in an in vitro model of cardiomyocytes showed that exogenous treatment of recombinant human Secretory Leukocyte Protease Inhibitor (rhSLPI) could protect cardiac cells from sI/R injury. A similar outcome was also exhibited in vascular endothelial cell injury from ischemia/reperfusion insults (Prompunt, 2016; Nernpermpisooth et al., 2017). In fact, the heart consists of approximately $70 \%$ non-myocytes and 30\% cardiac myocytes (Brilla et al., 1993). The cardiac fibroblast is in the non-cardiomyocyte population in the heart. Cardiac fibroblast not only plays role in cardiac development and remodeling, but it also regulates cardiomyocytes function and viability via cellcell interaction (Torre-Amione et al., 1996). It has been known that I/R injury causes cardiac cell death and could induce cardiac fibroblast injury and finally result in myocardial fibrosis (Chen and Frangogiannis, 2013). Thus, any strategy that is capable of 
protecting cardiac fibroblast from I/R injury could also protect cardiomyocytes. However, the cytoprotective effects of rhSLPI have never been investigated in sI/R-induced cardiac fibroblast cell death. Therefore, the aim of this study is to investigate the in vitro cytoprotective effects of rhSLPI on cardiac fibroblast subjected to simulated ischemia/reperfusion (sI/R) injury.

\section{MATERIALS AND METHODS}

\section{Adult rat cardiac fibroblast isolation and culture}

Adult Rat Cardiac Fibroblasts (ARCFs) were isolated from adult male Wistar rats $(200-250 \mathrm{~g})(\mathrm{n}=6)$ by collagenasebased enzymatic digestion using an adaptation of the method used by Kumphune et al. (Kumphune et al., 2010). The study protocol was approved by Naresuan University Animal Ethics committee (protocol license No.55 04 0005). The rats were anesthetized by intraperitoneal injection (IP) with pentobarbital $(300 \mathrm{mg} / \mathrm{kg}$ ) and heparin (150 units). The rat hearts were excised and initially perfused for $5 \mathrm{~min}$ with modified Krebs solution (solution A) containing $130 \mathrm{mM} \mathrm{NaCl}, 4.5 \mathrm{mM} \mathrm{KCl}, 1.4 \mathrm{mM} \mathrm{MgCl}, 0.4 \mathrm{mM}$ $\mathrm{NaH}_{2} \mathrm{PO}_{4}, 0.75 \mathrm{mM} \mathrm{CaCl}_{2}, 4.2 \mathrm{mM}$ HEPES, $20 \mathrm{mM}$ taurine, 10 $\mathrm{mM}$ creatine and $10 \mathrm{mM}$ glucose, $\mathrm{pH} 7.3$ at $37^{\circ} \mathrm{C}$ ). The hearts were then perfused with a calcium-free solution containing 100 $\mu \mathrm{M}$ EGTA for $5 \mathrm{~min}$, followed by perfusion with solution A containing $100 \mu \mathrm{M} \mathrm{CaCl}$ and $0.4 \mathrm{mg} / \mathrm{ml}$ Worthington type II collagenase for $10 \mathrm{~min}$. The ventricles were then cut into small pieces, which were incubated in $10 \mathrm{ml}$ of collagenase solution gassed with $100 \% \mathrm{O}_{2}$ for a further $7 \mathrm{~min}$ at $37^{\circ} \mathrm{C}$, with regular triturating. Then isolated myocytes were allowed to settle into a loose pellet and the supernatant containing cardiac fibroblasts were collected for further study. The ARCFs were resuspended with Dulbecco's modified Eagle's medium (DMEM) supplemented with $10 \%$ heat-inactivated fetal bovine serum (FBS), 100 unit/ $\mathrm{mL}$ of penicillin and $100 \mu \mathrm{g} / \mathrm{mL}$ streptomycin and allowed to settle for at least $2 \mathrm{~h}$ before removal of non-adherence cells. The adhered cardiac fibroblasts were cultured in complete medium for further experiments. Isolated cells were determined for fibroblast characteristics by used an immunofluorescence technique with a specific antibody against Vimentin (1:1000, Abcam).

\section{Simulated ischemia (sI) and determination of cell viability}

Simulated ischemia (sI) was induced by incubating ARCFs with a specifically modified Krebs-Henseleit buffer (137 $\mathrm{mM} \mathrm{NaCl}, 3.8 \mathrm{mM} \mathrm{KCl}, 0.49 \mathrm{mM} \mathrm{MgCl}, 0.9 \mathrm{mM} \mathrm{CaCl}_{2}$, and $4.0 \mathrm{mM}$ HEPES) with $20 \mathrm{mM}$ 2-deoxyglucose, $20 \mathrm{mM}$ sodium lactate, and $1 \mathrm{mM}$ sodium dithionite at $\mathrm{pH}$ 6.5. The control buffer was composed of Krebs-Henseleit buffer (137 mM NaCl, 3.8 $\mathrm{mM} \mathrm{KCl}, 0.49 \mathrm{mM} \mathrm{MgCl}, 0.9 \mathrm{mM} \mathrm{CaCl}_{2}$, and $4.0 \mathrm{mM}$ HEPES), supplemented with $20 \mathrm{mM}$ D-glucose, $1 \mathrm{mM}$ sodium pyruvate. Simulated ischemia (sI) was performed for $40 \mathrm{~min}$. After simulated ischemia was achieved, the ischemic buffer or control buffer was removed and the cells were subjected to reperfusion (sI/R) by replacing the ischemic buffer with complete medium and then incubated at $37^{\circ} \mathrm{C}, 5 \% \mathrm{CO}_{2}$ for $24 \mathrm{~h}$.

\section{Determination of cell viability}

ARCFs were cultured and treated with various concentrations of rhSLPI (Sino Biological, Inc., Beijing, China) at concentration of $0 \mathrm{ng} / \mathrm{ml}, 200 \mathrm{ng} / \mathrm{ml}, 400 \mathrm{ng} / \mathrm{ml}, 600 \mathrm{ng} / \mathrm{ml}$, $800 \mathrm{ng} / \mathrm{ml}$, and $1,000 \mathrm{ng} / \mathrm{ml}$, for $24 \mathrm{~h}$ before being subjected to $40 \mathrm{~min}$ of $\mathrm{sI} / \mathrm{R}$. At the end of reperfusion, the culture media was removed. Then, $0.5 \mathrm{mg} / \mathrm{ml}$ 3-(4,5-dimethylthiazol-2-yl)-2,5diphenyltetrazolium bromide (MTT) of reagent was added and incubated for $2 \mathrm{~h}$ at $37^{\circ} \mathrm{C}$. The formazan dye was finally solubilized with $500 \mu \mathrm{l}$ of Dimethyl sulfoxide (DMSO). The formazan dye was collected and the optical density (OD) was determined by a spectrophotometer at $\lambda 490 \mathrm{~nm}$ using DMSO as a blank. The relative percentage of cell viability was compared to the control group.

In addition, cell viability was also determined by using a trypan blue dye exclusion method. After the sI/R protocol, cells were then gently harvested and mixed with $0.4 \%$ trypan blue solution (Sigma, USA). The resulting cell suspension was counted by Countess II FL Automated Cell Counter (Invitrogen). The viable cells were expressed as a percentage of the total counted cells.

\section{Measurements of cellular injury}

The released-Lactate dehydrogenase (LDH) activity assay kit used in this study is a modified method based on the recommendations of the Scandinavian Committee on Enzymes (LDH SCE mod.). The kit was purchased from HUMAN (Wiesbaden, Germany). Ten microliters of culture medium were mixed with $1000 \mu \mathrm{l}$ of reaction buffer and incubated at $37^{\circ} \mathrm{C}$ for $5 \mathrm{~min}$. Then, $250 \mu \mathrm{l}$ of substrate reagent was added. The solution was mixed and the absorbance read after 1 min at $\Lambda 340 \mathrm{~nm}$. The mean absorbance change per minute $(\triangle A / \mathrm{min})$ was used to calculate LDH activity by the following formula;

$$
\text { LDH activity }(\mathrm{U} / \mathrm{I})=\Delta A / \min \times 20,000
$$

\section{Determination of cellular reactive oxygen species (ROS)}

ARCFs at a concentration of $1 \times 10^{5}$ cells $/ \mathrm{mL}$ were cultured in a 96 -well black plate at $37^{\circ} \mathrm{C}, 5 \% \mathrm{CO}_{2}$, and $95 \% \mathrm{O}_{2}$ until it reached $80 \%$ confluence. The culture media were removed and the cells were washed once with PBS prior to incubating with complete media containing $250 \mu \mathrm{M}$ 6-carboxy-2', $7^{\prime}$ dichlorodihydrofluorescein diacetate (carboxy-H2DCFDA) in a dark room for $30 \mathrm{~min}$ at $37^{\circ} \mathrm{C}$. The medium containing carboxyH2DCFDA was then removed and the cells were washed with PBS. For rhSLPI treatment, $200 \mu \mathrm{l}$ of completed medium containing various concentrations of rhSLPI were added and incubated for 1 $\mathrm{h}$ at $37^{\circ} \mathrm{C}$. Then, $250 \mu \mathrm{M}$ hydrogen peroxide $\left(\mathrm{H}_{2} \mathrm{O}_{2}\right)$ was applied to the cells and incubated for $30 \mathrm{~min}$ at $37^{\circ} \mathrm{C}$. The ROS activity was determined by measuring the fluorescence intensity with an EnSpire Multimode Plate Reader (PerkinElmer, Massachusetts, USA). The filter suitable for detecting the signal gave the excitation wavelength at $\lambda 498 \mathrm{~nm}$ and emission wavelength at $\lambda$ $522 \mathrm{~nm}$. The result was expressed in Arbitrary Unit (A.U.).

\section{Measurement of p38 MAPK activation and apoptosis regulatory proteins by Western blot analysis}

ARCFs cells were extracted in cold Radioimmunoprecipitation assay buffer (RIPA buffer). After centrifugation at $14,000 \mathrm{~g}$ for $15 \mathrm{~min}$ at $4^{\circ} \mathrm{C}$, the supernatants were collected, and then separated on $12 \%$ sodium dodecyl sulfate-polyacrylamide gels (SDS-PAGE) and transferred to 
polyvinylidene difluoride (PVDF) membranes. After blocking with 5\% skimmed milk, the membranes were blotted with antibodies against total p38 MAPK, phosphorylated-p38 MAPK, bcl-2-like protein 4 (Bax), B-cell lymphoma 2 (Bcl-2), $\beta$-actin (all from Cell Signaling, USA) using the Luminata ${ }^{\mathrm{TM}}$ Western HRP Substrates system (Merck, USA). The images were captured and quantified with Image Lab 4.0 software (Bio-Rad Laboratories), and the values were normalized to $\beta$-actin.

\section{Statistical analysis}

All values were expressed as mean \pm standard error of the mean (S.E.M). All comparisons were assessed for significance using One-way Analysis of variance (ANOVA), followed when appropriate by the Tukey-Kramer test. The statistical test was performed using commercially available software (Lab chart Prism version 5). A p-value of less than 0.05 was considered as statistically significant.

A

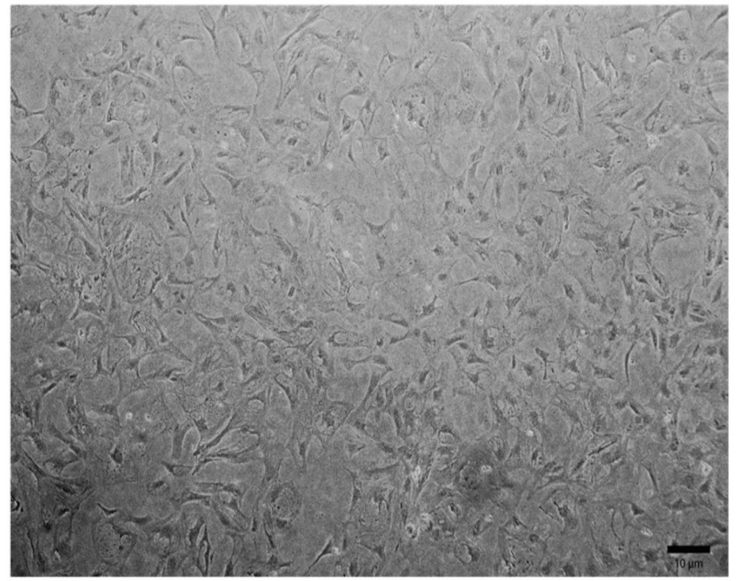

\section{RESULTS}

\section{Characterization of isolated ARCFs}

The results showed that isolated ARCFs showed the morphology of fibroblast cells with a flat, spindle shape with multiple processes spreading from the main body and lack of basement membrane (Figure 1A). Immunostaining of Vimentin, cell surface molecule specifically for fibroblast, showed that the isolated ARCFs exhibited Vimentin staining throughout the cell surface and this did not appear in the nucleus (Figure 1B). In addition, the determination of Vimentin expression by Western blot analysis showed that isolated ARCFs could express Vimentin protein at the molecular weight of $54 \mathrm{kDa}$ (Figure 1C). These results suggested that the isolated cells from ventricle expressed fibroblast phenotypes.
B

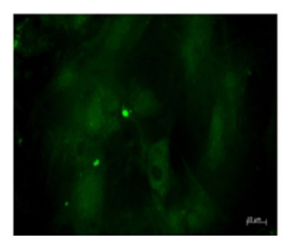

Vimentin-FITC 40X

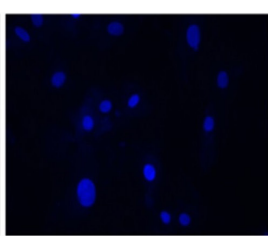

DAPI 40X

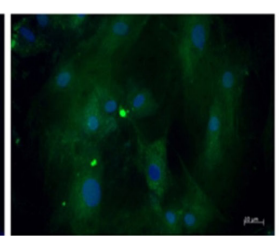

Merge 40X
C

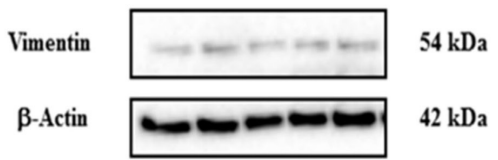

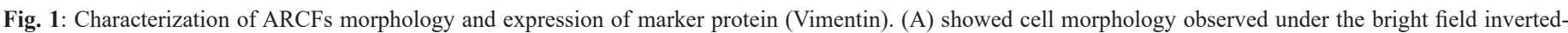

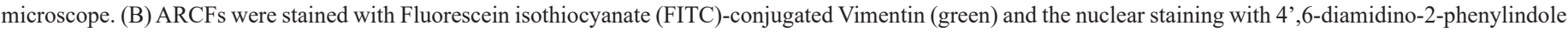

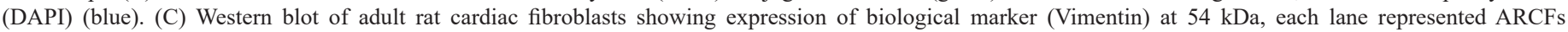
independently isolation.

\section{Treatment of rhSLPI in ARCFs reduced cell death and ROS production during $\mathbf{I} / \mathbf{R}$ injury}

The results showed that sI/R significantly decreased cell viability $(53.89 \pm 4.08 \%)$. Pre-treatment of rhSLPI prior to sI/R at concentrations of $400 \mathrm{ng} / \mathrm{mL}(64.44 \pm 2.08 \%), 600 \mathrm{ng} / \mathrm{mL}(67.50$ $\pm 4.88 \%), 800 \mathrm{ng} / \mathrm{mL}(68.06 \pm 5.41 \%)$ and $1000 \mathrm{ng} / \mathrm{mL}(69.31$ $\pm 4.92 \%$ ), significantly increased cell viability of the ARCFs when compared to the $\mathrm{sI} / \mathrm{R}$ group $(53.89 \pm 4.08 \%)(\mathrm{p}<0.05)$ (Figure 2A). Similar findings could also be observed in trypan blue dye exclusion assay. The results showed that pre-treatment of rhSLPI at concentrations greater than $200 \mathrm{ng} / \mathrm{ml}$ significantly increased cell viability (Figure 2B) and reduced cellular injury by released-LDH activity (Figure 2D). Treatment of rhSLPI in all concentrations could not reduce cell viability or increase cellular injury (Figure 2C, E).

\section{rhSLPI reduced I/R-induced intracellular ROS production}

To further investigate the cardioprotective effects of rhSLPI treatment during I/R injury, we next determined the effect of rhSLPI on intracellular ROS generation. The results showed that there was an increase in intracellular ROS production in the ARCFs after challenging with $\mathrm{H}_{2} \mathrm{O}_{2}$ when compared to the control $(28470 \pm 3827$ A.U. versus $2280 \pm 308.2$ A.U.). Pre-treatment of rhSLPI at concentrations of $600 \mathrm{ng} / \mathrm{mL}(21500 \pm 2002$ A.U.), 800 $\mathrm{ng} / \mathrm{mL}(21620 \pm 2348$ A.U.) $1,000 \mathrm{ng} / \mathrm{mL}(21070 \pm 2571$ A.U.) could significantly reduce intracellular ROS production $(\mathrm{p}<$ 0.05). However, pre-treatment of rhSLPI at $200 \mathrm{ng} / \mathrm{mL}$ and 400 $\mathrm{ng} / \mathrm{mL}$ did create a slight decrease in intracellular ROS production (Figure 3).

\section{Treatment of rhSLPI in ARCFs attenuated p38 MAPK phosphorylation and apoptotic regulatory protein}

Myocardial ischemia/reperfusion injury is a potent stimulant of p38 MAPK activation, which leads to myocardial cell death by apoptosis and myocardial cell injury (Kumphune et al., 2010). To determine the activation of p38 MAPK, Western blot analysis was performed in rhSLPI treatment prior to sI. The Western blot analysis was performed by using the specific antibody against phosphorylated p38 MAPK. 

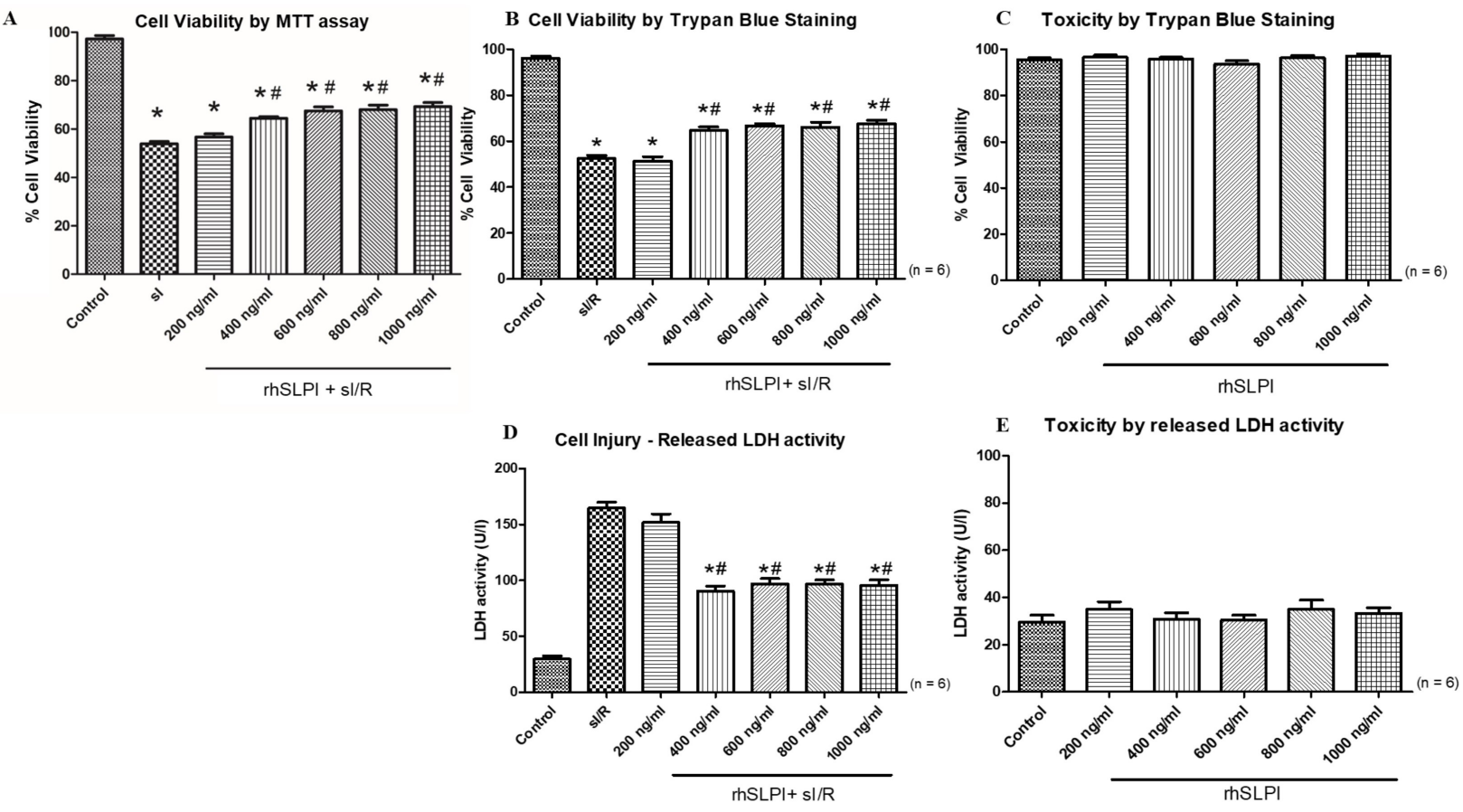

Fig. 2: Determination the effect of the rhSLPI treatment in ARCFs subjected to sI/R injury. (A) The percentage of cell viability by MTT assay of pre-treatment of ARCFs with various concentrations of rhSLPI. (B, C) Cell viability by trypan blue dye exclusion assay. (D, E) Cellular injury by released-LDH activity assay. Each bar graph represents means \pm S.E.M for each the 3 experiments. ${ }^{*} \mathrm{p}<0.05$ versus control group (ANOVA), $\# \mathrm{p}<0.05$ versus sI groups (ANOVA).

The result showed that p38 MAPK was strongly activated in response to simulated ischemia. Pre-treatment with $\mathrm{rhSLPI}$ at $1,000 \mathrm{ng} / \mathrm{mL}$ significantly reduced $\mathrm{p} 38 \mathrm{MAPK}$ phosphorylation when compared to sI group (Figure 4A, B). In addition, the apoptotic regulatory proteins $\mathrm{Bcl} 2$ and $\mathrm{Bax}$ were also determined. The results showed that pre-treatment with SLPI could significantly reduce Bax expression (Figure 4A, D), but not Bcl2 (Figure 4A, C). These results indicated that the treatment of rhSLPI in ARCFs could potentially attenuate p38 MAPK activation and Proapoptotic protein Bax expression.

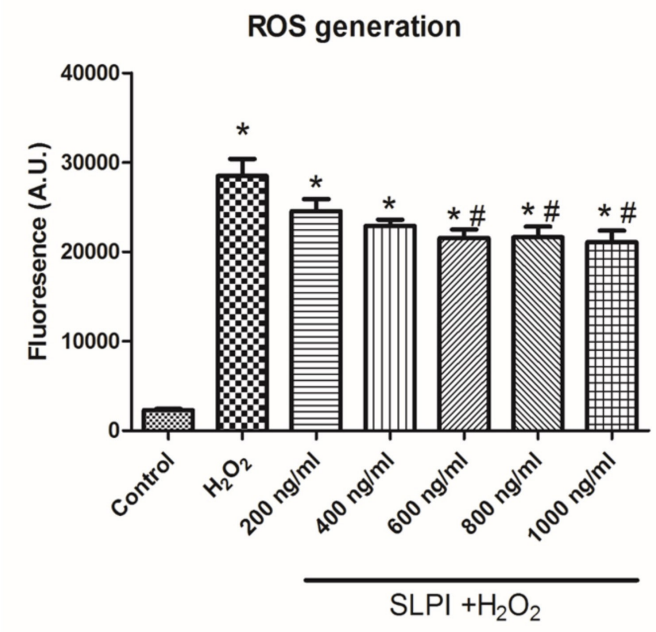

Fig. 3: The figure shows reducing intracellular ROS production. Each bar graph represents means \pm S.E.M for each the 3 experiments. ${ }^{*} \mathrm{p}<0.05$ versus control (ANOVA), $\# \mathrm{p}<0.05$ versus $\mathrm{H}_{2} \mathrm{O}_{2}$ treated group (ANOVA).

\section{DISCUSSION}

The present study highlights the cytoprotective effects of recombinant human secretory leukocyte protease inhibitor (rhSLPI) on an in vitro simulated ischemia/reperfusion (sI/R)induced cardiac fibroblast injury. The major findings of this study were the pre-treatment of rhSLPI prior to an in vitro sI/R could reduce sI/R-induced cardiac fibroblast cell death, intracellular ROS production, ischemic-induced p38 MAPK phosphorylation, and pro-apoptotic protein Bax.

The cardiac fibroblast plays a role as a sentinel cell by constructing scaffolding to hold other cells together (Nag, 1980). Fibroblasts play a key role after infarction as the outcome depends on the generation of a fibrous scar comprised largely of collagen (Sun and Weber, 2000). In the previous study, the secretome of cardiac fibroblast could reduce cardiomyocytes death in co-culture models, suggesting that there is communication between cardiomyocytes and cardiac fibroblast (Abrial et al., 2014). During I/R injury, it has been known that various protease enzymes were actively secreted from injured cardiac resident cells. These enzymes could harm not only the cells that secrete the protease itself but also injure the surrounding cardiomyocytes or cardiac fibroblast cells. These could expand the ischemic area as well as the infarct size (Jordan et al., 1999; Boudoulas and Hatzopoulos, 2009; Epelman et al., 2015). In addition, leukocytes and neutrophils infiltrate the ischemic area during reperfusion and secrete various serine protease enzymes, including cathepsin G, elastase, and trypsin (Kuckleburg and Newman, 2013). Necrotic cells also secrete intracellular protease enzymes, which contribute to heart tissue damage and ultimately impair cardiac function (Jordan et al., 1999; Boudoulas and Hatzopoulos, 2009; Epelman 
et al., 2015). Therefore, inhibiting protease activity may be a key strategy for preventing cardiac tissue injury following myocardial ischemia. We previously reported that rhSLPI overexpression in cardiomyocyte or rhSLPI treatment in isolated hearts could significantly reduce cell death, injury, as well as reduced infarct size (Prompunt, 2016). In addition, rhSLPI treatment could reduce ischemia-induced vascular endothelial cell death and

A

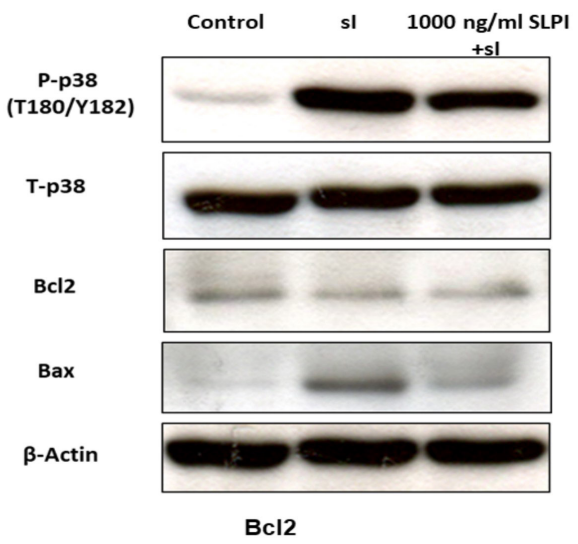

C

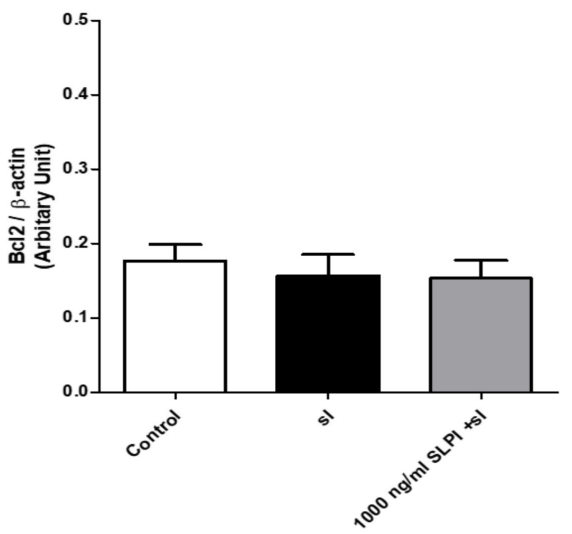

injury (Nernpermpisooth et al., 2017). However, the protective effect of rhSLPI on cardiac fibroblast sI/R injury has never been investigated. We hypothesized that rhSLPI could protect cardiac fibroblast from sI/R injury in vitro, which could possibly protect the heart from ischemic injury as well as limit post-infarction remodeling.

B

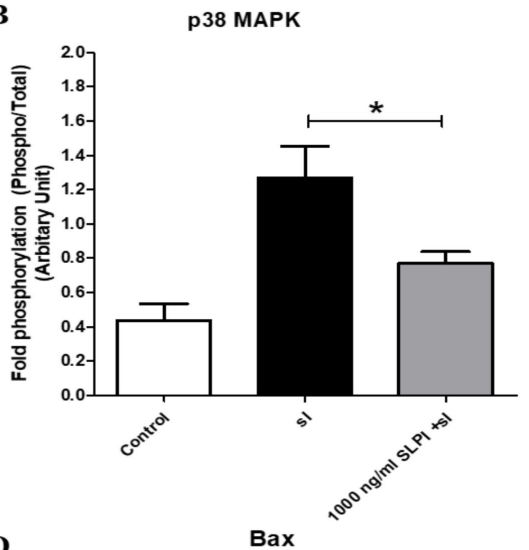

D

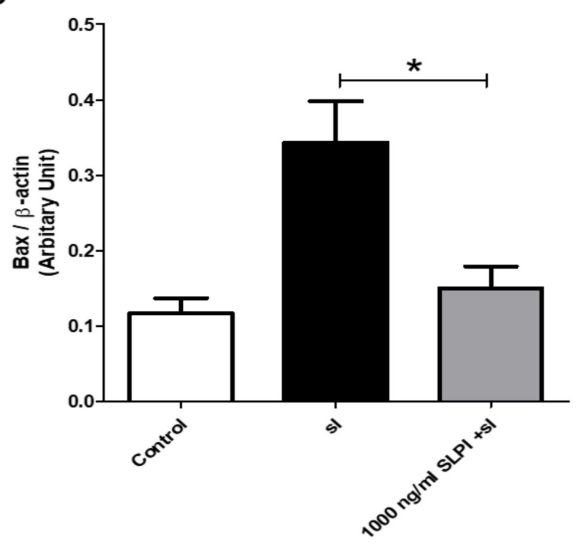

Fig. 4: Determination of cellular signaling in response to treatment of ARCFs with rhSLPI, subjected to sI/R. ARCFs were treated with rhSLPI at 1,000 ng/mL for 2 $\mathrm{h}$ before subjected to sI. The activation of $\mathrm{p} 38 \mathrm{MAPK}$ (A, B), anti-apoptotic protein Bcl2 (A, C), and proapoptotic protein Bax (A, D), was observed by Western blot analysis.

Recently, a new role of cardiac fibroblasts was discovered, in that, they act as sentinel cells that sense danger signals and enhance the inflammatory response to I/R (Kawaguchi et al., 2011). Under hypoxia/reoxygenation, inflammatory response was in cardiac fibroblasts through ROS production. In the present study, rhSLPI exhibited an antioxidant property to attenuate $\mathrm{H}_{2} \mathrm{O}_{2}$ induced cardiac fibroblast intracellular ROS production in a dosedependent manner. In addition, several reports demonstrated that SLPI treatment in several cell types could reduce inflammation and also showed anti-apoptotic effects (Seto et al., 2009; Subramaniyam et al., 2011). Reactive oxygen species (ROS) are responsible for the myocardial damage during both ischemia and the reperfusion period. The generation of ROS can be an indicator of apoptosis (Braunersreuther and Jaquet, 2012; Zhou et al., 2015). The reduction of intracellular ROS by rhSLPI treatment could be a crucial mechanism to regulate apoptosis in this $I / R$ injury. One of the possible explanations of anti-apoptotic effect of rhSLPI through modulation of intracellular ROS production. The excessive formation of ROS during I/R injury induces cardiac cell death directly by inducing cell membrane and protein damage (Hoffman et al., 2004) or indirectly by activating pro-apoptotic pathways (Ferrari, 1998; Hoffman et al., 2004). Proapoptotic Bax activation plays an important role in the apoptotic process. In this study, we found that rhSLPI treatment could significantly reduce Bax expression, although the anti-apoptotic protein, Bcl-2, was not altered. Therefore, rhSLPI that mediated more intracellular ROS reduction would attenuate more cardiac fibroblast apoptosis and subsequently limit further injury, which is crucial for infarcted area expansion, myocardial fibrosis and dysfunction (Kawaguchi et al., 2011).

The p38 MAPK is activated during cellular stresses, including I/R injury. Ischemia is a potent stimulant of p38 MAPK activation (Kumphune et al., 2012). Inhibition of p38 MAPK during ischemia reduces infarction and inhibits the production of inflammatory cytokines, such as Tumor necrosis factor alpha (TNF- $\alpha$ ), interleukin-1 (IL-1), and interleukin-8 (IL-8), which are known to aggravate ischemic injury (See et al., 2004; Clark et al., 2007; Kumphune et al., 2010; Kumphune et al., 2012). Moreover, 
reperfusion can re-activate p38 MAPK, perhaps in response to ROS stimulation (Son et al., 2013). Interestingly in sI/R, pretreatment cardiac fibroblast with rhSLPI reduced cell death; this was hypothesized that the decrease in cardiac fibroblast cell death following the treatment with rhSLPI was due to attenuation of $\mathrm{p} 38$ MAPK activation. The results of the current study indicated that the administration of rhSLPI prior to sI significantly attenuated the phosphorylation of p38 MAPK, and therefore protected cardiac fibroblast cells against sI/R injury.

There are several points that could be considered as limitations of this study. One of the interesting issues to consider is the fact that the results from this study were obtained solely from an in vitro study on the cytoprotective effects of rhSLPI in cardiac fibroblast cells subjected to sI/R. Further investigation should be performed to overexpress the rhSLPI gene in cardiac fibroblast, which then co-culture with cardiomyocytes in an attempt to determine if the secretion of rhSLPI from cardiac fibroblast could potentially protect cardiomyocytes. This could provide more information and is closely related to the real physiology of the heart.

\section{CONCLUSIONS}

In conclusion, we firstly demonstrated the cytoprotective effects of rhSLPI on primary isolated adult rat cardiac fibroblasts subjected to sI/R. The cytoprotective effects of rhSLPI could be due to the reduction of intracellular ROS production from $\mathrm{s} / \mathrm{R}$ injury. In addition, pretreatment of rhSLPI could reduce cell death by attenuation of $\mathrm{p} 38$ MAPK phosphorylation and reduction of pro-apoptotic protein Bax expression.

\section{ACKNOWLEDGMENTS}

This study was financially supported by Naresuan University Research endowment fund and National Research Council of Thailand (NRC) Grant I.D. Number R2558B067, Graduate student thesis grants from The Graduated School, Naresuan University. Lastly, we would like to thank Faculty of Allied Health Sciences, Naresuan University for providing Master degree scholarship for Nitchawat Paiyabhroma. We would like to thanks ProofRead4Sure service to English proofreading and editing.

\section{AUTHOR CONTRIBUTIONS}

Nitchawat Paiyabhroma and Sarawut Kumphune conceived and designed the experiments; Nitchawat Paiyabhroma performed the experiments; Nitchawat Paiyabhroma and Sarawut Kumphune analyzed the data; Sarawut Kumphune contributed reagents/materials/ analysis tools; Nitchawat Paiyabhroma, Nitirut Nernpermpisooth, and Sarawut Kumphune wrote and prepared the manuscript.

\section{CONFLICTS OF INTEREST}

The authors declare no conflicts of interest.

\section{REFERENCES}

Abrial M, Da Silva CC, Pillot B, Augeul L, Ivanes F, Teixeira G, et al. Cardiac fibroblasts protect cardiomyocytes against lethal ischemiareperfusion injury. J Mol Cell Cardiol, 2014; 68:56-65.

Boudoulas KD, Hatzopoulos AK. Cardiac repair and regeneration: the Rubik's cube of cell therapy for heart disease. Dis Model
Mech, 2009; 2(7-8):344-58.

Braunersreuther V, Jaquet V. Reactive oxygen species in myocardial reperfusion injury: from physiopathology to therapeutic approaches. Curr Pharm Biotechnol, 2012; 13(1):97-114.

Brilla CG, Reams GP, Maisch B, Weber KT. Renin-angiotensin system and myocardial fibrosis in hypertension: regulation of the myocardial collagen matrix. Eur. Heart J, 1993; 14(Suppl J):57-61.

Chen W, Frangogiannis NG. Fibroblasts in post-infarction inflammation and cardiac repair. Biochim. Biophys. Acta, 2013; 1833(4):945-53.

Clark JE, Sarafraz N, Marber MS. Potential of p38-MAPK inhibitors in the treatment of ischaemic heart disease. Pharmacol. Ther, 2007; 116(2):192-206

Epelman S, Liu PP, Mann DL. Role of innate and adaptive immune mechanisms in cardiac injury and repair. Nat. Rev. Immunol, 2015; 15(2):117-29.

Ferrari R. Effect of ACE inhibition on myocardial ischaemia. Eur. Heart J, 1998; 19(Suppl J):J30-5.

Hoffman JW, Jr., Gilbert TB, Poston RS, Silldorff EP. Myocardial reperfusion injury: etiology, mechanisms, and therapies. J Extra Corpor Technol, 2004; 36(4):391-411.

Jordan JE, Zhao ZQ, Vinten-Johansen J. The role of neutrophils in myocardial ischemia-reperfusion injury. Cardiovasc Res, 1999; 43(4):860-78

Kawaguchi M, Takahashi M, Hata T, Kashima Y, Usui F, Morimoto $\mathrm{H}$, et al. Inflammasome activation of cardiac fibroblasts is essential for myocardial ischemia/reperfusion injury. Circulation, 2011; 123(6):594-604.

Kuckleburg CJ, Newman PJ. Neutrophil proteinase 3 acts on protease-activated receptor-2 to enhance vascular endothelial cell barrier function. Arterioscler Thromb Vasc Biol, 2013; 33(2):275-84.

Kumphune S, Bassi R, Jacquet S, Sicard P, Clark JE, Verma S, et al. A chemical genetic approach reveals that p38alpha MAPK activation by diphosphorylation aggravates myocardial infarction and is prevented by the direct binding of SB203580. J. Biol. Chem, 2010; 285(5):2968-75.

Kumphune S, Chattipakorn S, Chattipakorn N. Role of p38 inhibition in cardiac ischemia/reperfusion injury. Eur J Clin Pharmacol, 2012; 68(5):513-24.

Nag AC. Study of non-muscle cells of the adult mammalian heart: a fine structural analysis and distribution. Cytobios, 1980; 28(109):41-61.

Nernpermpisooth N, Prompunt E, Kumphune S. An in vitro endothelial cell protective effect of secretory leukocyte protease inhibitor against simulated ischaemia/reperfusion injury. Exp Ther Med, 2017; 14(6):5793-800.

Prompunt E. Roles of secretory leukocytes protease inhibitor on myocardial ischemia/reperfusion injury: Naresuan University; 2016 (PhD Thesis).

Schneeberger S, Hautz T, Wahl SM, Brandacher G, Sucher R, Steinmassl O, et al. The effect of secretory leukocyte protease inhibitor (SLPI) on ischemia/reperfusion injury in cardiac transplantation. Am J Transplant, 2008; 8(4):773-82.

See F, Thomas W, Way K, Tzanidis A, Kompa A, Lewis D, et al. p38 mitogen-activated protein kinase inhibition improves cardiac function and attenuates left ventricular remodeling following myocardial infarction in the rat. J Am Coll Cardiol, 2004; 44(8):1679-89.

Seto T, Takai T, Ebihara N, Matsuoka H, Wang XL, Ishii A, et al. SLPI prevents cytokine release in mite protease-exposed conjunctival epithelial cells. Biochem. Biophys. Res. Commun, 2009; 379(3):681-5.

Son Y, Kim S, Chung HT, Pae HO. Reactive oxygen species in the activation of MAP kinases. Methods Enzymol, 2013; 528:27-48.

Subramaniyam D, Hollander C, Westin U, Erjefalt J, Stevens T, Janciauskiene S. Secretory leukocyte protease inhibitor inhibits neutrophil apoptosis. Respirology, 2011; 16(2):300-7.

Sun Y, Weber KT. Infarct scar: a dynamic tissue. Cardiovasc Res, 2000; 46(2):250-6. 
Torre-Amione G, Kapadia S, Benedict C, Oral H, Young JB, Mann DL. Proinflammatory cytokine levels in patients with depressed left ventricular ejection fraction: a report from the Studies of Left Ventricular Dysfunction (SOLVD). J Am Coll Cardiol, 1996; 27(5):1201-6.

Zhou T, Chuang CC, Zuo L. Molecular Characterization of Reactive Oxygen Species in Myocardial Ischemia-Reperfusion Injury. BioMed Res. Int, 2015; 2015:864946.
How to cite this article:

Paiyabhroma N, Nernpermpisooth N, Kumphune S. The

Recombinant Human Secretory Leukocyte Protease Inhibitor (SLPI) protects cardiac fibroblasts injury against an in vitro ischemia/reperfusion injury. J App Pharm Sci, 2018; 8(06): 156162. 